\title{
Right and Wrong in the Conduct of Science
}

\author{
Mukunda P Das* and Frederick Green ${ }^{\dagger}$
}

\begin{abstract}
Science, in particular physics, is a collective enterprise and is so because it is, itself, a fruit of the exquisitely social nature of human living. So it is inevitable to encounter ethical issues in the natural sciences, since the contest of differing interests and views is perennial in its practice, indeed essential to its momentum. The crucial ethical question always hangs in the air: How is the truth best served? In this paper we describe some ethical aspects of our own discipline of science: their cultural context and the bounds which they delineate for themselves, sometimes in transgression. We argue that the minimalist ethic espoused in science, namely loyalty to truth, is a bellwether for the much wider, more problematic, and more vital consequences of ethics - and its failure - in human relationships at large.
\end{abstract}

Keywords: Science, Physics, Philosophy, Right and wrong, Ethics, Human relationships

* Department of Theoretical Physics, The Australian National University Canberra, ACT 0200, Australia; mukunda.das@anu.edu.au

† School of Physics, The University of New South Wales, Sydney, NSW 2052, Australia 


\section{Introduction}

"Knowledge is not a loose-leaf notebook of facts. Above all, it is a responsibility for the integrity of what we are, primarily of what we are as ethical creatures." (Jacob Bronowski) [1]

The general outlook of ethics with respect to science, for instance physics, is little different from that for any other human endeavour. The function of ethics in the study of Nature can be viewed as consisting of two parts: one is external to the enterprise and the other is intrinsic to it. External ethics in the context of doing science, as well as technology, works at the intersection of the social good with the promise and the risks carried by scientific progress. Despite its clearly value-laden origin, the term "scientific progress" is morally neutral from its own internal viewpoint. By "intrinsic" and "internal" we identify those processes within a scholarly community by which truth is to be found and safeguarded. Although, here, it is as professional physicists that we analyse various points, regular public reporting makes it abundantly clear that ethical issues of concern to practicing physicists apply to the conduct of natural science generally. The state of physics is, from our point of view, emblematic.

Turning briefly to the external aspect of scientific ethics, few would dispute that advances in knowledge have provided, and continue to provide, not only astonishing benefits but also some of the thorniest and most alarming dilemmas ever to confront the global community. One need only recall the problems set by nuclear proliferation, or by environmental degradation through uncritical devotion to any single technology as the saviour of a complex situation. Analysis of such dilemmas is a much broader and deeper task than the one to which we limit ourselves here. In this paper we address ethics within science proper. What ideals does the scientific ethic embody? How is this ethic upheld? What are the consequences of violation? How does human frailty come into such abstract pursuits?

The aims of physics - of science - as a realm within scholarship are quite narrow in comparison with the tasks of moral philosophy, or of law, or of much humanly oriented scholarship. The reason lies in 
the criteria for what sets good science apart from the less good, as well as a tradition that views its subject and initio as morally neutral. Science asserts that its conclusions are strictly objective; not contingent upon the observer. There are fields of scholarship, on the other hand, in which reflexivity may be central to their intellectual processes; a degree of interplay between subject and object that renders their study both more profound and more formidable [2]. (Some philosophers have challenged the assertion of scientific objectivity, but as a claim it is at least empirically justified; most of us travel by plane unworried whether the physics of powered flight may fail depending on the pilot's confidence.)

Validation in science presupposes an utterly disinterested, amoral arbiter: Nature. The ideal of science is to discern and disseminate the facts about physical reality; that web of complex interlocking phenomena within which, as both sentient and rational creatures, "we live and move and have our being". Even so, such a bareboned ideal provides no guarantee of rock-solid certitude.

Hard knowledge requires sustained uncompromising effort, not just technically but in overcoming unconscious preconceptions that may be held personally and, often, communally. Again, Bronowski finds the words: "Science is a tribute to what we can know, although we are fallible" [3]. Upon that sensibility hangs the coherence of the ethic that animates science.

In the following section we review the foundational ideas, and ideals, by which the discipline of science - natural philosophy first grew and now defines itself. We draw on some of the earliest writing on the method of science. The philosopher-scientist Descartes, in particular, argued that ethics infuses the praxis, if not the matter, of science from the beginning. Next we discuss how this ethic, centred upon the integrity of factual truth, is worked out in the actual realm of contesting interests; human ambitions which, notoriously, may fall short of ethical perfection. Thus one must ask:

‡ The twin roles of discovery and communication are symbiotic; at its best science is a shared, democratic action in which trustworthy knowledge is sifted not only by peer discussion, but also in teaching fresh minds who, in the process of acquisition, may bring to light facts unknown to themselves and to their mentors. 
What accommodations might we live with, in practice? What can never be countenanced? What, indeed, are the bounds on the scientific ethic? The fourth section begins with our survey of a topical area of modern science with considerable ethical implications: nano-technology. We use this to introduce the basic kinds of moral problems facing scientists in their daily work. These are put in sharper relief by some recent failures of scientific integrity. Finally, we end with a summary of our paper.

\section{Intellectual Origins}

“The heavens declare the glory of God." (Psalm 19:1)

Seeking out truth, spiritual, poetic, or scientific, is never dissociated from the primal sense of wonder that motivates our searches, even after years of daily familiarity. Nor is moral sensibility able to be divorced from this because aesthetics and ethics are twin intimations, for us, of a coherent and harmonious reality beyond the subjective and beyond social convention. Here we take all this on faith, as the common ground for moral perception. Its explication sits outside our competence.

On the other hand, the human sphere is largely structured by human interests, which may stray far from even an imperfect ethic. It can be argued that Nature, by implicit definition, is "perfect". By the same token, Nature exists beyond moral categories; for instance, philosophers distinguish between "natural" evils that hurt us physically but cannot possess malice, and "moral" evil that damages us in multiple ways: in mind and body, and in one's core humanity whereby the notion of malice enters [2].

Human motivations, however, are neither perfect nor above morality. To our understanding, the codification of moral issues raised by living, in an ideal or at least a near-ideal pragmatic sense is the concern of the philosophy of ethics. This calls for clarifying the context and authenticity of ideas of right and wrong in various circumstances, as also for making their essential distinction perspicuous. It is the road to "right thinking": typically not through our desires, but through what is truly coherent. 
Insofar as physical knowledge now comes into the picture, René Descartes advanced a novel view:

Thus, all Philosophy is like a tree, of which Metaphysics is the root, Physics the trunk, and all the other sciences the branches that grow out of this trunk, which are reduced to three principal, namely, Medicine, Mechanics, and Ethics. By the science of Morals, I understand the highest and most perfect which, presupposing an entire knowledge of the other sciences is the last degree of wisdom.

One need not agree with the frankly reductionist accent of his programme (as many scientists are still liable to do), to appreciate Descartes' more profound point. In the starkest terms, ethics is circumscribed by our own creatureliness, our own physicality. This is a reality so "earthbound" - and as such, traditionally viewed with disfavour in certain older systems of thought - that it needed his penetrating intellect to envision it as not just a metaphysical, but as a metamoral fact.

From there Descartes proceeds to his punch line. The ground of our existence and thought may be physical but the spiritual as well as the affective and aesthetic superstructures based upon it demand the most refined concentration and our highest possible intellectual commitment. A less reductionist understanding might receive this in terms of Aristotle's "the whole is greater than the sum of its parts".

The wellspring of scientific ethics consists in this: seek the truth as best as you can; neither hide nor inflate it; defend its integrity when necessary. The basic guidelines are no different from those regulating the pursuit of all scholarship at its finest. Indeed, it is no different from those which underlie the rule of law - of our rights and obligations vis a vis one another - in every just society. We have tried to encapsulate the scope of scientific ethics. What are its bounds? This is a question that cannot be answered by observing the practice of science within its own terms. We must look outwards to perceive how science is embedded within culture itself. Science does not exhaust culture. Culture is decidedly far more than science. 
No long meditation is needed to conclude that the ideals of science are abstracted from the wider experience of human existence, and not the other way around. Sadly, that does not mean that the demands of scientific ethics cannot clash with other imperatives. The Galileo affair provides one of the most tragic and enduring examples of such a clash, as in our time the Evolution "debate" still does, in some narrower religious circles.

Taking a cue from Descartes, we assume as scientists that ethics is grounded in our physical circumstance - yet not logically reducible to it. A more modern, eloquent restatement of the Cartesian commitment to the human meaning of the physical sciences is due to the mathematician, poet and philosopher Jacob Bronowski [1]. Bronowski dwells in great detail on the relationship of science not only to ethics but to art and literature, attempting to harmonise a vision of the whole. In the spirit of Descartes and Bronowski we now proceed to give examples of ethics played out in the life of contemporary science.

\section{Where Angels Fear To Tread}

"Science should leave off making pronouncements: the river of knowledge has too often turned back on itself." (Sir James Jeans)

Since Galileo, Descartes, Newton, and Leibniz the sheer success of the scientific advance, with its pervasiveness in culture and economic productivity, continually raises an insidious kind of moral hazard for practitioners: the onset of a certain hubris. This reached its climax in the materialist triumphalism of the late 19th Century. The temptation still lingers to extrapolate the successes of science into ambit claims that science will in due course explain everything (one is led to ask: including itself?). Nothing is to be left over; every other mode of thinking will be either subsumed or discarded.

A contemporary example comes from the series of science books for non-specialists, coauthored by the eminent cosmologist Stephen Hawking. A uniquely endowed spirit, Hawking in his passion for knowledge has not only opened doors to a possible unification of quantum theory and gravitation; his daily monumental struggle 
with chronic, incapacitating illness, steeled by a drive to arrive at deep knowledge at any personal cost, has no precedent known to us in the history of physics, and few parallels in scholarship at large.

In a recent book "The Grand Design" Hawking and Leonard Mlodinow assert that modern theoretical physics has supplanted philosophy, at least in principle, when addressing large-scale epistemic questions, such as accounting for the origin and fate of the Universe: "Traditionally these are questions for philosophy, but philosophy is dead" [4]. Do Hawking's brilliant theoretical insight and formidable personal courage validate announcing the death of (metaphysical) philosophy through a vision of an incorruptible flawlessness and universality for scientific understanding? No, they do not. While in no way diminishing Hawking's stature or his passion, it is simply that he and Mlodinow are not justified in that claim. Their contention is itself an epistemological assumption, outside the domain of science and potentially as open to critical deconstruction [5] as the earlier, analogous heralding of "the end of history" by Francis Fukuyama in the context of geo-strategic politics. Here, belief looks to replace knowledge - while attempting to pass for realism.

Stripped of their formal and instrumentalist façades, essays in this mode, while possibly beginning in erudition, end in advocacy for one or other theory of absolutely everything. But in explaining all things they "explain" nothing - at least in the narrow scientific sense claimed as their gift. It follows that, by any useful definition, they fall outside physics as novel and ingenious exercises in speculative metaphysics of a peculiarly old-fashioned kind: metaphysics with a blunt axe to grind.

How is exaggeration of the scope of science an ethical problem? It is not the integrity of physics that is misrepresented; it is the broader human significance that it undoubtedly possesses, but whose genuinely valuable qualities live outside its descriptive constraints. The Hawking-Mlodinow thesis amounts to a distortion of reality. Limited, albeit robustly testable, claims to a comprehension of Nature are universalised without warrant, if perhaps unconsciously, beyond what science is actually equipped to say. They do this in a kind of romantic vision that may well 
captivate many, including its proponents, yet which, in the end, gains no further scientific understanding. We would argue that, in this instance, the legitimacy that is the measure of science is stretched beyond its bounds.

We do not suggest that physicists are alone in the temptation to inflate their subject beyond the reasoned constraints of scholarship. There are more extreme examples, past and present, notably in biological fields such as the so-called neuro-sciences. It prompts one to ask: On what basis are audiences enjoined to deprecate the discipline of philosophy in any of its forms? It is surely not on the basis of an oddly self-negating philosophical stance.

In our opinion, it is an ethical failure for the integrity of science to be co-opted into a sort of beauty competition with philosophical tradition; that denigrates the former, not the latter. It obscures its proper character behind a set of non sequiturs that make up a caricature, not an honest portrait. It fails to elucidate the true work of science, for the huge audience of non-specialists who desire, and deserve, well-considered information.

\section{Brave New Worlds}

“There's plenty of room at the bottom." (Richard Feynman) [6]

Physics and chemistry provide an explanation for the scale of life on Earth. Under local conditions of gravity, geology, temperature and so on, we more or less emerged with the right size to sustain functional and adaptable brains. Our species' endless capacity for imagination and foresight, however, radically outstrips our ability to explicate it in comprehensible terms (so far). One clear determinant of such cerebral functions is the vast combinatorics of billions of neurons interconnected through even vastly more numerous pathways. It is this very model, drawn from Nature that forms just one source of inspiration for today's nano-sciences.

Old allegorical tales, such as Gulliver in Lilliput, became familiar friends to most of us as children. Yet not until Feynman's seminal article [6] were scientific minds directed in earnest to inventing and building systems whose parts are hundreds of thousands of times 
tinier (typically ranging from the size of an atom up to several micrometres) than the most delicate instruments one can craft directly with hand and eye. Mastering the engineering and control of devices at scales far smaller than neurons, will depend on being the able to interconnect them (not necessarily by hard wiring) into coherent, "distributed" information systems whose combinational complexity and therefore behavioural richness might rival a human brain. By any measure of technical prowess, this is a very seductive proposal - and this is not even to visit the possibility of symbiosis between biological and physico-chemical nano-technologies. But it is good to bear in mind that this is still fancy, not reality.

The moral issues raised by the prospect of a mature and widely diffused nano-science cannot be minimised; hypothetically, at least, we might one day find ourselves sharing our rational space with an artificial consciousness superior to, even more nuanced in perception than, our natural one. Nevertheless any such moral considerations fall outside science and do not differ in quality (nor in potential for tragedy) from historical precedents. We recall one of the worst to date: the way in which the unparalleled destructiveness of nuclear energy in various forms was grossly misunderstood, leading to the diplomatic nightmare of curbing its spread for wholesale military use.

As our goal is to highlight only those issues internal to science, we look at the formulation and conduct of contemporary research policy within the field of nano-science. To what extent has it presented a balanced, scientifically informed picture of the field's importance - and of its risks - in the quest for public and private research support?

To set the technical backdrop for the ethics, we recall two highlights in nano-developments since Feynman's early sketch of a programme. An enormous advance in the ability to control and accurately replicate nano-construction came with the invention in 1981 of the scanning tunneling microscope (STM) by Binnig and Rohrer [8]. It is the first in a generation of instruments exploiting delicate but highly controllable quantum effects. The STM not only serves to map surface detail at sub-atomic resolution, but more significantly to actively manipulate - and build to order - the fundamental functional units at the atomic level. The STM 
vindicated Feynman's conjecture that true nano-scale engineering is indeed possible, despite the STM's and all other current techniques' remaining extremely far from viable for industrial manufacturing. (The hurdle, of course, is to exceed a by thousand fold or more the massive degree of integration already achieved through mature silicon electronics.)

At the level of high policy, the most significant impact on nanoscience arrived in 2000 with the Clinton Administration's declaration of it as a major funding priority, enshrined in the United States' "National Nanotechnology Initiative" [9] (NNI). This signaled a global rush by many kinds of entities, public and private, with enough fiscal and technical resources to try to emulate the US effort, though few of them have matched its size.

Commitments of the intensity, if not the scale, of the NNI have now been sustained in many countries for longer than a decade. A few ingenious, if not genius-level, ideas and thousands of talented graduates have been brought to fruition. What else has emerged, in strict terms of what was firmly promised (the unprecedentedly powerful "quantum computer" for one) as the revolution that would become a commonplace within a single decade?

To our mind, the scientific realities of nano-science so far do not exactly match the heady enticements conjured up to promote it; were this not the case, our tale here would be a radically different one. On the contrary it would seem that the ethics which ought to underwrite any such massive social investment, namely that of keeping faith with sober scientific reality has not been well served. Much has been promised, with hardly any proofs of concept; much more has been expended, in good faith, over fifteen years or so. So far, little has come about to show for it.

This is not a great surprise as, with rare exceptions, endeavours of this nature cannot avoid being capital-hungry and labourintensive. $\S$ Yet the solid basis to justify profligacy was missing. For,

\$ There is one delightful instance where low-key "string-and-sealing-wax" physics has outclassed far more elaborate "big-dollar" competitors. Geim and Novoselov [9] were the first to isolate and study graphene (single sheets of graphitic carbon with extraordinary physical properties, and 
nano-technology has not as yet experienced its own incontrovertible, paradigmatic revolution as was the case, say, with nuclear developments following the discovery of fission. While the eventual harnessing of fission was clearly still speculative in 1938, all the cards were on the table as to its real and prodigious energy release. Even then, it took the existential threat from an implacable enemy to really empower the nuclear project.

The promise of nano-technology rests on imagination. There is nothing in the least wrong with this, since science lives by the vision of scholars; but on its own it cannot substitute for the backing of hard fact (and, not infrequently, an acute emergency - such as global warming) as serious impetus for a sustained all-out crash programme. To set up a modest research laboratory costs several million dollars and, to run it, a few hundred thousand annually over perhaps ten to fifteen years. Consequently this emerging field has been vulnerable to strong funding rivalries, and to overoptimistic salesmanship by most of the protagonists [10].

Above, we have covered an instance of one type of bound on the ethics of physics and science. To put it succinctly: do not portray possibility as reality! It follows that if one lacks both substantial and rational evidence for one's claim to public support, and a long term commitment to the underlying ideal (not simply to political manoeuvring), one should not misrepresent a largely imaginative agenda as outweighing equally worthy goals that are more factually grounded. As with the Hawking-Mlodinow programme reviewed above, much nano-technology is a case of faith in a nebulous future masquerading as knowledge in the concrete present.

\section{Beyond The Edge of Flatland}

"Judge not, that ye be not judged." (Matthew 7:1)

considered a fundamental building block) by inspired use of plain household adhesive tape. Their low-key methodology to obtain pure graphene gained them the Nobel Prize in Physics for 2010. 


\section{A. An academic fraud}

One might say that any ethical failure in the promotion of nanoscience, as we have portrayed it, is a second-order defect. There may have been public misrepresentation of its objective status and potential but no actual distortion or confection of scientific data. First-order failures are those in which the factual integrity of a discipline is directly subverted.

For some time, scientific fraud has been considered an unwelcome yet unremarkable activity in certain life-related sciences, notoriously in medical research. Typically, clinical studies of a new treatment will involve a great amount of statistical processing of data gleaned from test populations that are mostly not very large. Conversely the error margins are so much the larger so any correlation to be found between cause and effect may be tenuous. There seems to exist an opportunity to hide any mischief within the data "noise", to colour or even manufacture results hoping to cultivate a reputation for innovation and originality, or one's standing with funding bodies, or indeed purely to survive the press of inhuman and quite unforgiving commercial interests.

It is sobering to admit that the cooking of results - fraud - is not the preserve of disciplines where it could more readily be hidden by an unavoidable fuzziness in methodology. We are going to discuss a severe recent case of scientific cheating within that hardest of the "hard" sciences, our own field of nano-physics, a field capable of producing astoundingly accurate measurements, with error bars much too small to allow space for playing up. The case is now known as the Hendrik Schön Affair.

Jan Hendrik Schön was a brilliant German graduate who pioneered the study of active electronic devices made of thin layers of exotic organic materials. These layers resemble graphene in that the motion of charges within them is effectively two-dimensional; a true "Flatland" world of structures that form the raw material for most of nano-technology. His extraordinary results in fabricating and measuring these novel organic conductors led to a prestigious fellowship at the Bell Laboratories in New Jersey: one of the most innovative, highly competitive "hothouses" for ambitious creative 
young researchers in solid-state physics and the most sophisticated kinds of electronics imaginable.

At Bell Labs Schön continued, indeed greatly expanded, his run of outstanding accomplishments in the laboratory. Paper after paper on new and unique properties of his organic samples appeared in the most select journals, bearing his authorship and those of his supervisors and colleagues. The Schön phenomenon was as mesmeric as it was meteoric. His star faltered and fell the day that a watchful reader noticed that the plots of electrical properties of one of his samples, published in one paper, had an astonishing resemblance to plots from a quite different material, published in earlier unrelated work from Schön et al. In fact this anomaly was noted by several sharp readers, who duly aired their suspicions. It began to look as if ethical behaviour in this field might have been pushed beyond the edge of propriety, into blatant fabrication. In short order Bell Labs halted the project and suspended Schön. Amid the community furore, the Laboratories commissioned an expert investigative panel of senior, external peers.

Exhaustive enquiries found Jan Hendrik Schön clearly guilty of serial fraud [12]. He was of course dismissed for his betrayal of faith, and the panel's judgments and recommendations published. The crushing, albeit merited, punishment of a wrecked career and public censure were not the last of it for Schön, however. His alma mater the University of Konstanz took the further, to us needlessly vindictive, step of revoking his doctoral degree (whose scientific integrity was never in question [13]).

We ask once more how ethics was served, and honour fully restored, in the Bell-sponsored investigation. While indispensable for upholding the public integrity of our discipline, the inquiry, though open, could not help being inquisitorial to a degree and, sadly if inevitably, an implicit exercise of establishment prerogatives. We conclude that while the ethical standard of scholarly behaviour may have been upheld in the letter, the spirit of the panel's deliberations reveals itself in a slightly different light.

The official report on Schön at Bell ascribes to him the entire responsibility for malfeasance; he was, after all, the one investigator who had complete access to the intricacies of the data. Now the role 
and conduct of his co-authors had to be scrutinized, since they must have given explicit assent to their share in the publication of the (faked) results. In the outcome the co-authors, be they senior or junior, were exonerated by the experts while Schön was left to "hold the baby", so to speak.

Granted that Schön's colleagues were not party to the cheating, the clean slate accorded them by the panel of experts begs additional questions whose answers are nowhere to be found. (1) Just what quality and maturity of oversight should have been expected, at least from the senior co-authors, as well as those specialist peer reviewers who missed anomalies in the papers which the readership evidently did not? (2) The "oversight" was spectacularly absent; why? (3) Testimonies to the panel by all the other authors assert that they were wholly distanced from the central activities of data gathering and interpretation that define every published work. Then, being in effect little more than passengers on Schön's bandwagon, why were they co-authors at all?

The latter point dwells particularly on the ethics of the attribution and due recognition of scholarly work, on which we will have more to say. To ascribe, much less to arrogate, to oneself authorship of work to which one has not materially contributed, is an easy road for many of us to follow for various reasons, none of them scientific. Yet it is a form of untruth, rightly seen as scientifically unethical.

On the proprieties of shared authorial responsibility the Bell committee appears to have tried to have it both ways, as indeed did Schön's exonerated senior colleagues. For, either the putative coauthors were not authors in the true scholarly meaning or, if they were, they failed signally in their implied collaborative duty and therefore did, and do, indeed share morally the main perpetrator's guilt.

As practitioners ourselves, we feel it is not unreasonable to infer a certain unconscious element of self-absolution in the expert panel's exonerating exercise, glossing over a common prerogative of senior academics: namely, the bending of the authorship rules (hardly ever - of course). It is virtually to confess, sotto voce: "We all do it, what's so bad about it?" While this may be the practice and 
arguably a much less catastrophic offence than outright fabrication, the physics community should at least admit to falling short of its own ideals in this respect. Nobody's hands are squeaky clean. If we are collectively too arrogant or perhaps too embarrassed to be honest about this "small" lapse, our enterprise may not crash but the guarantee of its trustworthiness on larger matters is eroded anyway. Credibility suffers.

Whether or not other, possibly more highly placed, Hendrik Schöns have been generating further mischief, no-one can say unless they are detected. That is pure speculation. But uncovering it depends entirely on collective watchfulness so that, in this way, fraud truly becomes the responsibility of all. This is not to advocate a permanent state of mutual paranoia; there is overmuch of such a mentality as things stand already. But although it is trite to say that ethics begins and ends with the individual, it is nevertheless so. And one lesson from the Schön affair comes as a reminder that human frailty, either directly or via the community, never fails to be an "up-close-and-personal" issue: one that hovers over our best intentions - and perhaps those of our colleagues down the corridor. Should one trust one's neighbours? Yes. Should one trust them when advancing a proposition that is far too good to be true (as has happened with regard to aspects of nano-science)? Maybe not.

\section{B. From Fraud, on to Theft}

Our final reflection goes to the nature of authorship and its abuse, which also poses a serious challenge to ethics in science. The truth is always to be served. This means not just that the record of what we find out about Nature must be honest and open. The record of who discovered which phenomena, of who wrote what, is itself constrained by the same injunction: respect the facts.

To indulge in plagiarism, stealing someone else's rightful claim to authorship is as nasty an instance of theft as having one's wallet removed in a street mugging. It may even be more serious than that, since it robs an author of intangibles beyond a price, such as credit for originating an idea. It parasitises hard-won reputations and possibly puts livelihoods at risk. 
In the academy itself, one of the worst social effects has been the bad example set before students and junior staff by powerful leaders, perhaps at the apex of a university or research institute, who end up exposed as plagiarists themselves. Their high office may require them to adjudicate cases of plagiarism by students and at times by scholars, who are all accountable to the hierarchy. It is the worst hypocrisy when a plagiarist censures another plagiarist, the latter paying the due penalty while their judge may go unscathed. But not always!

Monash University in Melbourne was forced in 2002 to seek the resignation of its vice-chancellor, Professor David Robinson, following confirmation that he had engaged in plagiarism in the writing of two books during his previous academic career in Britain [14]. A similar case from 2003 in India [15] provoked the enforced resignation of Professor B. S. Rajput, vice-chancellor of Kumaon University, but only after an international appeal to the President of India via a letter signed by four Nobel laureates. Though the Professor attempted to blame a student for the plagiarism - in its entirety - of a paper previously published in Physical Review D in 1996, it was ascertained that the responsibility for the breach was his. Much more recently [16], the Science Adviser to the Prime Minister of India has also come under scrutiny over implications of plagiarism, in relation to which he has issued an apology for his unwitting involvement.

How many scientists, who believe and assent to the normative role of ethics in their field, act to make sure that this role remains robustly in its central place? How to deal constructively with fraud, plagiarism, and other transgressions? We cannot offer any systematic theory of how ethics should be protected. Much less can we, nor would we wish to, offer all-encompassing solutions. We decline to do so convinced that, just like charity, ethical behaviour begins at home. That is, our hope rests first in a continuing attempt to behave as honestly as one can in one's own academic life. For instance, an honest peer reviewer is bound to set aside any antipathy, either personal or intellectual, to assess a submission on its terms. Others will likewise judge more properly whether a scientific life is lived usefully; but we are masters of our own conscience here. 
Second, it is crucial to communicate to students, passionately and with conviction, the ethic of our discipline contemporaneously with its technical intricacies. In fact this is a natural part of teaching; one does not need to delve too far into any worthwhile subject to discover that lazy solutions invite the cutting of corners, and that cutting corners invites playing fast and loose with the integrity of a methodology. These pitfalls are not mere abstractions, but engage a student's personal sense of what it is "right" to do. While, in this vein, the ethical pedagogy may emerge more or less smoothly, its lesson may still prove to be a stony path. So be it; the scientific ethic demands no less but, at least, perfection is not the prerequisite to our faithfulness. As countless saints have shown it is the latter that holds the key to the former, so we have hope for good.

\section{Summary}

"Every judgment in science stands on the edge of error, and is personal." (J. Bronowski" [1]

"Elegance is not what we are trying for." (Ludwig Wittgenstein) [11]

At the end of this paper we turn to words of Bronowski again, and of Wittgenstein. We have stressed two aspects of the scientific ethic. We have recalled the rigid standard to which honest science is called, one no less demanding than every other ethical system developed to deepen and broaden our lives. At the same time, this is a deliberately limited ethic whose intent is to foster specific knowledge rather than generalized belief: a preference for answering the "how" ahead of the "why", even though these often interpenetrate each other.

Humans are chronically incomplete. We undershoot our own ideals all the time and always will, because the criteria for what is ideal move forward through our own striving toward them. Yet we do not despair. We seek what is perfect even knowing that our finiteness may trap us, and that today's flash of insight anyway will be superseded tomorrow.

It is in collective wisdom that we find not just solace but an antidote to fallible subjectivity and a measure of objective 
consistency, as Bronowski goes on to assert. Some Christians like to say that they are not perfect, just forgiven. Likewise, physicists and scientists in general might well say that they are not perfect, just upheld in honesty by the integrity of their scholarly community. Science has fallen short more often than history records (we all have anecdotes, intimations that we keep to ourselves). Above, we have reviewed some failures in our present time.

They are not pretty, and further analysis is needed though it might give cause for alarm about negative and systemic behavioural trends that they revealed. Nevertheless, the fact that someone, somewhere, inevitably discovers a concealed failure and witnesses to it (often at some cost) gives us precisely the kind of hope that is enshrined in the scientific ethic.

At the end, also, we return to the parallel existence of a scientific aesthetic. This undoubtedly exists even if editors of scientific journals discourage authors from waxing too lyrical. The point is that beauty, like curiosity, informs the sensibility of a good scientist (but unless one is Einstein, Dirac, Chandrasekhar or Feynman, physicists tend to be shy about discussing this freely). Science, however, has an ethic that tells us, as does Wittgenstein, that clarity and honesty matter even more than elegance. Many elegant theories have proved to be wrong. Not all successful theories are distinguished by an incomparable economy and beauty. The ethical message, then, is: truth above all. Beauty? Yes, but beauty later.

\section{References}

Bronowski, Jacob. The Ascent of Man. BBC Press, London, 1973.

Gaita, Raimond. A Common Humanity. Routledge, London, 2000.

Bronowski, Jacob. op. cit. Ch. 11

Hawking, Stephen and Mlodinow, Leonard. The Grand Design. Bantam Books, New York, 2010.

Tallis, Raymond. "Philosophy isn't dead yet." The Guardian, London, 27 May 2013. http://www.theguardian.com/ commentisfree/2013/may/27/ physics-philosophyquantumrelativity-einstein. 
Feynman, Richard P., "Plenty of Room at the Bottom" Engineering and Science (Caltech), XXIII, 5 (1960). See also http:/ / feynman.caltech.edu/plenty.html.

"Graphene Researchers Geim and Novoselov Win Nobel Prize in Physics" ScientificAmerican.com, 5 October 2010.

Web. http://www.scientificamerican.com/article.cfm?id=geim -novoselov-physics-novel

"The Nobel Prize in Physics 1986". Nobelprize.org. Nobel Media AB 2014. Web. 7 Jan 2015. http://www.nobelprize.org/ nobel_prizes/ physics/laureates/1986/

National Nanotechnology Initiative: The Initiative and its Implementation Plan, NSTC NSET Report, July 2000. NSTC-NNI Subcommittee, Washington, 2000. Web. http://www.nano.gov/ node/243

Lok, Corie. "Nanotechnology: Small Wonders" Nature 467, 18 (2010). doi:10.1038/467018a.

Wittgenstein, Ludwig. The Blue and Brown Books. Blackwell, Oxford, 1958.

University of Toronto. "Report of the Investigation Committee on the Possibility of Scientific Misconduct in the Work of Hendrik Schön and Coauthors", September 2002. Web. http://www.engineering.utoronto.ca/Assets/AppSci+Digital+Assets/p df/GradStudents+Ethics/Schoen_Full+Report.pdf

"Schön scandal." Wikipedia, The Free Encyclopedia, Inc. 8 December 2014. Web. 28 January 2015

"Great Moments in Academic Fraud." TheAustralian.com. 5 July 2012. Web. 7 Jan 2015.

"Scientific Plagiarism in India." Wikipedia, The Free Encyclopedia, Inc. 3 Jan 2015. Web. 7 Jan 2015.

"No Science in 'Cut and Paste'." The Hindu. 10 March 2012. Web. 7 Jan 2015. 